ONLINE MUTATION REPORT

\title{
Autosomal recessive erythropoietic protoporphyria in the United Kingdom: prevalence and relationship to liver disease
}

\author{
S D Whatley, N G Mason, M Khan, M Zamiri, M N Badminton, W N Missaoui, T A Dailey, \\ H A Dailey, W S Douglas, N J Wainwright, G H Elder
}

J Med Genet 2004;41:e105 (http://www.jmedgenet.com/cgi/content/full/41/8/e105). doi: 10.1136/jmg.2003.016121

$\mathrm{E}$ rythropoietic protoporphyria (EPP; MIM 177000) is an inherited disorder of haem biosynthesis characterised by the onset in early childhood of lifelong acute photosensitivity of sun-exposed skin. ${ }^{1}$ It results from partial deficiency of ferrochelatase (FECH; E.C. 4.99.1.1.), which leads to accumulation of protoporphyrin IX in erythrocytes, plasma, skin, and liver. Up to $35 \%$ of patients have mildly abnormal biochemical tests of liver function, while liver failure caused by the hepatotoxic action of protoporphyrin complicates about $2 \%$ of cases. ${ }^{2-5}$

Over 70 mutations in the $F E C H$ gene have been identified in EPP families (Human Gene Mutation Database: http:// www.hgmd.org/). ${ }^{6-10}$ Most individuals who are heterozygous for these mutations are asymptomatic, despite having halfnormal FECH activities. ${ }^{11}$ For protoporphyrin to accumulate sufficiently to cause photosensitivity, reduction of $\mathrm{FECH}$ activity to below a critical threshold of about $35 \%$ of normal is required. ${ }^{11}{ }^{12-14}$ In most patients, this additional reduction results from inheritance of a low expression FECH allele trans to a severe mutation. ${ }^{10}{ }^{15-18}$ The low expression allele is the $\mathrm{C}$ variant of a single nucleotide polymorphism (SNP; IVS3-48C/ $\mathrm{T}$ ) in intron 3 of the $F E C H$ gene. ${ }^{18}$ Because the IVS3-48C allele is common in the general population, being present in about $11 \%$ of the white inhabitants of France, ${ }^{18}$ inheritance trans to a severe FECH mutation occurs within EPP families at a frequency that is high enough to produce a pattern of inheritance of overt EPP resembling an autosomal dominant disease with incomplete penetrance.

Although co-inheritance of an IVS3-48C allele appears to explain the occurrence of photosensitivity in most EPP families, 8101718 alternative mechanisms may reduce FECH activity to below threshold activity in some patients. These include autosomal recessive inheritance with an $F E C H$ mutation on both alleles, ${ }^{15}{ }^{19-23}$ deletion of an FECH gene secondary to haematological malignancy, ${ }^{24}$ and a dominantnegative effect from the mutant FECH allele. ${ }^{25}$

The prevalence of autosomal recessive EPP has not been established. FECH measurements in a small number of families suggest that up to $20 \%$ of patients may have autosomal recessive disease, ${ }^{19}{ }^{22}$ but mutational analysis of patients with EPP suggests a lower figure ${ }^{69}{ }^{26}$; mutations on both alleles have been identified in only three families..$^{20} 23$ In one of these families, two siblings developed liver failure ${ }^{21}$ and it has been suggested that severe FECH mutations on both alleles may predispose to end stage liver disease during adolescence. ${ }^{21} 2728$ This suggestion has been disputed on the grounds that protoporphyric liver disease was not present in the two other families with autosomal recessive $\mathrm{EPP}^{20}{ }^{23}$ and that all other patients with severe liver disease in whom mutations have been identified have been heterozygotes. ${ }^{9}{ }^{29}$

Here we describe the molecular investigation of 105 randomly selected patients with EPP and one patient with

\section{Key points}

- Erythropoietic protoporphyria (EPP) is an inherited disorder of haem biosynthesis resulting from partial deficiency of ferrochelatase (FECH) and characterised by early onset of lifelong acute photosensitivity.

- Over 70 mutations in the FECH gene have been identified in EPP families. Inheritance of an IVS3-48C allele trans to the mutation appears to explain photosensitivity in most families, though alternative mechanisms sometimes may be involved.

- A total of 105 randomly selected patients with EPP and one patient with liver disease caused by EPP were molecularly investigated.

- The prevalence of autosomal recessive disease among patients with EPP in the United Kingdom is 3\% $195 \%$ confidence interval: 1 to 7 ). This mode of inheritance is the usual explanation for overt EPP in patients without an IVS3-48C allele; autosomal recessive EPP may carry a much higher risk of severe liver disease than the more usual form

- Autosomal recessive EPP appears to be clinically indistinguishable from EPP in which an FECH mutation on one allele is trans to a low expression IVS3-48C allele. Screening all new patients with EPP for absence of the IVS3-48C allele to select those with the T/T genotype for mutational analysis of the $\mathrm{FECH}$ gene should identify most patients with autosomal recessive disease.

liver disease caused by EPP. We show that the prevalence of autosomal recessive disease among patients with EPP in the United Kingdom is 3\% (95\% confidence interval: 1 to 7 ); that this mode of inheritance is the usual explanation for overt EPP in patients without an IVS3-48C allele; and that autosomal recessive EPP may carry a much higher risk of severe liver disease than the more usual form, particularly when one of the mutations abolishes FECH activity.

\section{METHODS}

Patients and control subjects

We investigated 106 apparently unrelated patients (61 female, 45 male; mean age at investigation: 24 years, range

Abbreviations: ALT, alanine aminotransferase; AST, aspartate transaminase; EPP, erythropoietic protoporphyria; $\mathrm{FECH}$, ferrochelatase; GGT, gamma glutamyl transpeptidase; SNP, single nucleotide polymorphism 
1-67 years) with photosensitivity in whom the diagnosis of EPP was established by demonstrating increased concentrations of protoporphyrin (greater than $80 \%$ free protoporphyrin) in erythrocytes (mean $31.4 \mu \mathrm{mol} / \mathrm{l}$ erythrocytes, range 3.7-97.4 $\mu \mathrm{mol} / \mathrm{l}$; normal $<1.7 \mu \mathrm{mol} / \mathrm{l}$ ) and plasma. All were resident in the UK. One patient (patient A) had deteriorating liver function (see Case Report section below). The other 105 patients were randomly selected, unrelated patients with overt disease, referred for confirmation of diagnosis; no patient in this group had evidence of overt liver disease, deteriorating liver function, or haematological malignancy. To assess the prevalence of different modes of inheritance of EPP, we obtained samples of EDTA-anticoagulated blood from these 105 patients. Samples were also obtained from the relatives of patient $\mathrm{A}$, from the relatives of two of the 105 patients, and from 100 randomly selected control subjects without biochemical evidence of porphyria from the same catchment area. Ethical approval for the study was received from Bro-Taf Health Authority Local Ethical Committee.

\section{DNA analysis}

Genomic DNA was extracted from whole blood using the QIAamp DNA purification kit (Qiagen, Crawley, UK). Patients and control subjects were genotyped for the FECHIVS3-48C/T polymorphism ${ }^{18}$ using sense (5'-GTGTTGTGTGTCCTGAATCTT) and antisense (5'GAATGGTGCCAGCTTACTAAA) primers to obtain a $282 \mathrm{bp}$ amplimer which was digested with TseI to produce two fragments at 29 and $253 \mathrm{bp}$ from the $\mathrm{T}$ allele and three fragments at 29, 64, and 189 bp from the C allele. Absence of the IVS3-48C allele was confirmed by direct sequencing of the PCR-amplified fragment of genomic DNA used for digestion with restriction enzyme.

For identification of mutations, all exons with 20-300 bp flanking sequence and $1300 \mathrm{bp}$ of the promoter region of the FECH gene were PCR amplified (primers and conditions are available from the authors). PCR-amplified double-stranded DNA was purified from agarose gels using the QIAquick gel extraction kit (Qiagen, Cawley, UK) before being cycle sequenced using fluorescent ddNTPs (BigDye) and an ABI Prism 3100 Genetic Analyzer (PE Biosystems, Warrington, UK). The presence or absence of mutations was confirmed by sequencing both strands. Fluorescence dosage analysis of exon 4 of the FECH gene was carried out using exon 17 of the $D M D$ gene as internal standard and exon-specific primers, one of each pair labelled with 5'FAM. Fluorescent PCR products were separated and quantified with an ABI Genescan 310 analyser.

\section{Expression and characterisation of mutant FECHs}

To characterise the in vitro activity of the mutant FECHs, Quikchange mutagenesis (Stratagene) was employed to recreate the mutations in the previously described wild type ferrochelatase expression plasmid, pHisTF20E. ${ }^{30}$ The mutant enzymes were purified as described previously. ${ }^{30}$ Enzyme activity was measured using a real time direct spectroscopic assay. $^{31}$

\section{Other methods}

Erythrocyte and plasma porphyrins were determined by standard methods. ${ }^{32}$

\section{Numbering system}

Nucleotides are numbered from the cDNA sequence of human FECH (GenBank accession number D00726) with the A of the ATG initiation codon as " +1 ".

\section{RESULTS}

\section{Case report}

Patient A presented at 4 years of age with itching, painful erythema and swelling affecting sun-exposed skin which had been occurring from the age of 1 year. The eruption started each year in early spring, persisted during the summer months, and then subsided. There was no family history of photosensitivity. On examination, there was mild linear and varioliform scarring over the nose. His erythrocyte protoporphyrin concentration was increased at $17.4 \mu \mathrm{mol} / \mathrm{l}$ with normal urinary porphyrin, porphobilinogen, and 5aminolaevulinate concentrations, confirming the clinical diagnosis of EPP. Advice was given about the use of sunblock creams and appropriate protective clothing. At 6 years of age, he was commenced on beta-carotene due to worsening symptoms during the summer months. Biochemical tests of liver function were mildly deranged: aspartate transaminase (AST) 59 IU/l (normal: 5-45 IU/1), alanine aminotransferase (ALT) 75 IU/l (normal: 5-40 IU/l), total bilirubin $16 \mu \mathrm{mol} / \mathrm{l}$ (normal: $1-22 \mu \mathrm{mol} / \mathrm{l}$ ).

At the age of 9 years, he was admitted to hospital during July with a painful, red, swollen face, abdominal discomfort, and loose stools. On examination, he had tender erythema and oedema of his face, associated with linear scarring on the nose and cheeks, and extensive varioliform scarring on the forehead and dorsal aspects of his hands. His haemoglobin was $11 \mathrm{~g} / \mathrm{dl}$ with mild hypochromia and microcytosis. Biochemical tests of liver function were normal. His symptoms settled rapidly and annual desensitisation with ultraviolet-B phototherapy was initiated to improve his restricted lifestyle.

Evidence of increasing liver damage was first noted at the age of 12 years: AST 109 IU/l, ALT 184 IU/l, gamma glutamyl transpeptidase (GGT) $131 \mathrm{IU} / \mathrm{l}$ (normal: 5-30 IU/1), and total bilirubin $7 \mu \mathrm{mol} / \mathrm{l}$. Erythrocyte protoporphyrin was $36.0 \mu \mathrm{mol} / \mathrm{l}$, plasma protoporphyrin $83 \mathrm{nmol} / \mathrm{l}$ (normal: $<10 \mathrm{nmol} / \mathrm{l})$. He complained of recurrent abdominal discomfort over the next 3 months. An abdominal ultrasound scan was normal. He was started on cholestyramine $4 \mathrm{~g}$ daily.

By the age of 13 years, his symptoms had worsened, with an episode of painful, swollen arms after walking outside for just $10 \mathrm{~min}$ on a cloudy day. His erythrocyte and plasma protoporphyrin had increased to $45.7 \mu \mathrm{mol} / \mathrm{l}$ and $727 \mathrm{nmol} / \mathrm{l}$, respectively, and there was evidence of further liver damage: AST 219 IU/l, ALT 319 IU/l, GGT 255 IU/l, and total bilirubin $18 \mu \mathrm{mol} / \mathrm{l}$. His haemoglobin was $11.2 \mathrm{~g} / \mathrm{l}$ and ferritin $18 \mu \mathrm{g} / \mathrm{l}$. He was referred for early assessment as a potential candidate for liver transplantation. A liver biopsy was not considered necessary at this stage. His symptoms are well controlled 1 year later (AST 106 IU/l, ALT 164 IU/l, GGT 125 IU/l).

Analysis of genomic DNA from patient $A$ and his asymptomatic mother (erythrocyte protoporphyrin: $1.2 \mu \mathrm{mol})$ showed him to be a compound heterozygote for novel nonsense $(215 \mathrm{~T}>\mathrm{C}[\mathrm{L} 72 \mathrm{X}])$ and missense $(778 \mathrm{~T}>\mathrm{C}$ [F260L]) mutations of the FECH gene (table 1). He was homozygous for the T variant of the FECH IVS3-48C/T SNP. To determine the effect of the missense mutation on FECH activity, the F260L mutant was expressed in E. coli and shown to decrease activity to $50 \%$ of normal (table 2 ).

\section{Prevalence of the $\mathrm{FECH}$ IVS3-48C allele in patients with overt EPP and control subjects}

We screened for autosomal recessive disease by searching a randomly selected group of 105 unrelated patients with overt EPP for patients who had not inherited an IVS3-48C allele. This strategy was based on the assumption that all patients possessing this allele are heterozygous for a severe $F E C H$ mutation in trans to it. ${ }^{16-18}$ 
Table 1 FECH alleles in autosomal recessive EPP

\begin{tabular}{|c|c|c|}
\hline Patient & Allele 1 & Allele 2 \\
\hline A & $215 \mathrm{~T}>\mathrm{C}[\mathrm{L}$-72X]; IVS3-48T & $778 \mathrm{~T}>\mathrm{C}$ [F260L]; IVS3-48T \\
\hline B & $416 \mathrm{~A}>\mathrm{T}$ [Q139L]; IVS3-48T & $416 \mathrm{~A}>\mathrm{T}$ [Q139L]; IVS3-48T \\
\hline C & 707G >A [C236Y]; IVS3-48T & $1137 \mathrm{G}>\mathrm{C}[\mathrm{K} 379 \mathrm{~N}] ;$ IVS3-48T \\
\hline $\mathrm{E}$ & $163 \mathrm{G}>\mathrm{T}[\mathrm{G} 55 \mathrm{C}] ;$ IVS3-48C or $\mathrm{T}^{*}$ & $1001 \mathrm{C}>\mathrm{T}[\mathrm{P} 334 \mathrm{~L}] ;$ IVS3-48C or T* \\
\hline
\end{tabular}

Table 3 shows that there is a strong association between the low expression IVS3-48C allele and clinically manifest EPP in UK patients $\left(\chi^{2}=97 ; \mathrm{p}<0.001\right)$, as recently reported for French ${ }^{18}$ and Swedish ${ }^{10}$ patients. A total of 102 (97\%) of our 105 patients had at least one IVS3-48C allele whereas this allele was present in only 13\% of the control group (allele frequency: $6.5 \%$ ), a figure close to the $11 \%$ found for the white French population. ${ }^{18}$

\section{Identification of autosomal recessive EPP}

Three unrelated patients (patients B, C, and D) with overt EPP had not inherited the low expression IVS3-48C allele (table 3). Patients B and C had a sibling with EPP, but none had any other family history of the disease or parents known to be consanguineous. To investigate the molecular mechanism for EPP in these patients, we sequenced their FECH genes. Sequencing and gene dosage analysis showed that patient $\mathrm{B}$ was homozygous for a novel missense mutation in exon 4 (416A>T [Q139L]) (table 1). Patient C was found to be a compound heterozygote for novel missense mutations in exon 7 (707G $>$ A [C236Y]) and exon $10(1137 G>C$ [K379N]) (table 1). Activities of the Q139L, C236Y, and K379N mutants ranged from $12 \%$ to $50 \%$ of the activity of wild type enzyme (table 2).

Family investigation showed that the low expression IVS348C allele was trans to the C236Y FECH mutation in one of the parents of patient D who had no history of photosensitivity and a normal erythrocyte protoporphyrin concentration $(1.7 \mu \mathrm{mol} / \mathrm{l})$. No mutation was identified on either FECH allele of patient D. Deletion of the entire gene was excluded by showing that she was heterozygous for two intragenic SNPs (287G/A, IVS9-50delA). The cause of this patient's EPP remains to be established.

To confirm that the patients with an IVS3-48C allele were heterozygous for FECH mutations, the FECH gene was sequenced in 14 patients selected at random from the 102 patients in this group (table 3). A single mutation was identified in 10 of these patients, including four mutations that have not previously been reported in EPP (table 4). No mutation was found in three patients, one of whom was homozygous for the IVS3-48C allele. The other 13 patients were all IVS3-48C/T heterozygotes. Unexpectedly, two missense mutations were identified in patient $\mathrm{E}, 163 \mathrm{G}>\mathrm{T}$ [G55C] and 1001C $>$ T [P334L] (table 1); G55C was also present in one of the three previously published cases of autosomal recessive EPP. ${ }^{20}$ Family investigation was not possible, so we

\begin{tabular}{lll}
$\begin{array}{l}\text { Table } 2 \\
\text { FECHs }\end{array}$ & Expression in E. coli of mutant and wild type \\
\hline FECH & $\begin{array}{l}\text { FECH activity } \\
\text { min/nmol } \mathrm{FECH} \text { ) }\end{array}$ \\
mutation & mesohaem/ & $\begin{array}{l}\text { Percent wild type } \\
\text { activity }\end{array}$ \\
\hline Wild type & $2.5,2.7$ & 100 \\
Q139L & 0.46 & 18 \\
C236Y & 0.30 & 12 \\
F26OL & 1.36 & 52 \\
K379N & 0.97 & 37 \\
\hline *FECH activities are means of triplicate measurements.
\end{tabular}

were unable to confirm that this patient was a compound heterozygote or to determine which mutation was trans to the IVS3-48C allele.

\section{DISCUSSION}

Previously, only three EPP families have been identified in which patients had mutations on both alleles. ${ }^{2021} 23$ Here we describe an additional four unrelated patients with autosomal recessive EPP, as defined by the presence of a deleterious FECH mutation on both alleles (tables 1 and 2).

To determine the prevalence of autosomal recessive EPP, we have carried out the first investigation of a large, randomly selected group of unrelated patients for the presence of mutations on both $\mathrm{FECH}$ alleles. Because detailed analysis of the complete $45 \mathrm{~kb} F E C H$ gene in such a large group of patients was not practicable, we initially screened for the presence of IVS3-48C alleles and then carried out mutational analysis on patients lacking this allele. Implicit in this strategy is the assumption that all patients having an IVS3-48C allele are heterozygous for a disabling FECH mutation. Although there is support for this assumption from previous studies of EPP families, ${ }^{16-18}$ we checked that it held for our patients by sequencing the FECH gene in a randomly selected subgroup of 14 patients who had inherited an IVS3-48C allele.

Using this approach, we identified autosomal recessive EPP in three of 105 patients to give a minimum prevalence of $3 \%$ (95\% confidence interval: 1 to 7 ) for this pattern of inheritance in UK families. This figure is consistent with previous evidence from molecular analysis of the FECH gene that autosomal recessive EPP is uncommon ${ }^{6}{ }^{26}$ and suggests that family studies based on FECH activity alone ${ }^{1922}$ overestimated its frequency, possibly due to the inherent imprecision of FECH measurement and the consequent difficulty of distinguishing between the effect of a low expression IVS3-48C allele and an FECH mutation.

Our data also provide independent confirmation of the recent report by Gouya et $a l^{18}$ that clinically overt disease is strongly associated with inheritance of an IVS3-48C allele (table 3). This finding supports the hypothesis that clinical expression of EPP usually requires this allele trans to a severe FECH mutation. ${ }^{18}$ In the small number of patients with the IVS3-48T/T genotype, other mechanisms must be responsible for decreasing FECH activity to below the threshold for photosensitivity. In our series, three of four patients with this genotype had FECH mutations on both alleles suggesting that autosomal recessive disease is the usual explanation. The most important complication of EPP is liver disease, caused by accumulation of protoporphyrin in the liver and usually progressing rapidly to death from end stage liver failure unless treated by orthotopic liver transplantation. ${ }^{245}$ This complication occurs in about $2 \%$ of patients but, at present, there is no reliable method for the early detection of those at high risk.

One of our patients (patient A) with autosomal recessive disease was identified because molecular analysis was prompted by clinical and biochemical features characteristic of the initial phase of protoporphyric liver disease during which failure of hepatic excretion leads to increasing 
Table 3 FECH IVS3-48C/T polymorphism in EPP patients and control subjects

\begin{tabular}{llllllll}
\hline & & \multicolumn{3}{l}{ Genotype } & & & \multicolumn{2}{l}{ Allele } \\
\cline { 6 - 7 } Group & No. of subjects & T/T & T/C & C/C & & T & C \\
\hline EPP & 105 & $3(2.8)$ & $97(92.4)$ & $5(4.8)$ & & $103(49.1)$ & $107(50.9)$ \\
Control & 100 & 87 & 13 & 0 & $187(93.5)$ & $13(6.5)$ \\
\hline
\end{tabular}

Figures in parentheses are percentages.

Table 4 FECH mutations identified on only one allele in patients with EPP heterozygous for the IVS3-48C/T SNP

\begin{tabular}{|c|c|c|c|c|}
\hline Exon/intron & Mutation & Effect & No. of patients & Reference \\
\hline 1 & 40delG & Stop+72 bp & 1 & Todd et $a^{\beta 7}$ \\
\hline 1 & 53delT & Stop $+54 \mathrm{bp}$ & 1 & This paper \\
\hline 3 & $\mathrm{IVS} 3+2 \mathrm{~T} \rightarrow \mathrm{G}$ & Splice defect & 1 & Sarkany et $a^{p 1}$ \\
\hline 4 & IVS4+1G $\rightarrow$ C & Splice defect & 2 & Rufenacht et al \\
\hline 7 & $734 \mathrm{~T}>\mathrm{C}$ & L245P & 1 & This paper \\
\hline 9 & 945 delA & Stop+335 bp & 1 & This paper \\
\hline 9 & $1077 G>A$ & Splice defect & 2 & This paper \\
\hline
\end{tabular}

accumulation of protoporphyrin in the liver and progressive liver damage. ${ }^{25} 9$ Liver disease in EPP may be associated with particularly low FECH activities. ${ }^{21}$ The missense mutation (F260L) in our patient decreased FECH activity to 50\% of normal (table 2) and was trans to a null (L72X) mutation. Assuming a similar effect in human cells in vivo, the predicted FECH activity in this patient would be about $25 \%$ compared to about 34\% for L72X trans to an IVS3-48C allele.

Our findings support the view that autosomal recessive EPP carries a higher risk of severe liver disease than other forms of EPP. ${ }^{21}$ Liver disease has complicated EPP in two of the seven families proven by molecular analysis to have autosomal recessive disease $e^{202123}$ (table 1). Analysis of the mutations in 19 unrelated patients with severe liver disease who were heterozygous for $F E C H$ mutations has shown that missense mutations are present in only two of 19 patients, whereas about $25 \%$ of all mutations identified in EPP are missense mutations. ${ }^{92}{ }^{23}$ In this context, it is intriguing that two of the three patients with autosomal recessive EPP who did not have missense mutations on both alleles have both had liver disease ${ }^{21}$ (table 1).

All our patients with autosomal recessive disease had a missense mutation on at least one allele (table 1). Of the six missense mutations in our patients, only two have previously been identified: G55C in a compound heterozygote with autosomal recessive disease ${ }^{20}$ and $\mathrm{P} 334 \mathrm{~L}$ as the only mutation in a patient with EPP. ${ }^{6}$ The P334L mutant was shown to have $19 \%$ of normal activity. ${ }^{6}$ The four novel mutations that we identified all retained some FECH activity (12-50\% of normal; table 2). In contrast, functional studies of missense mutations previously identified on only one allele in EPP, apart from $\mathrm{P} 334 \mathrm{~L}$, have shown much lower or undetectable FECH activities. ${ }^{6}{ }^{34-36}$ Some or all of the milder mutations that we identified may only cause disease in homozygotes or when trans to another FECH mutation and thus be truly recessive. The functionally most severe missense mutation that we identified (C236Y) (table 2) had not caused clinically overt EPP when trans to an IVS3-48C allele in the father of patient $\mathrm{C}$ indicating that this combination, and presumably similar combinations with less severe mutations, may not lead to disease in heterozygotes.

In conclusion, autosomal recessive EPP appears to be clinically indistinguishable from EPP in which an FECH mutation on one allele is trans to a low expression IVS3-48C allele but may carry a much higher risk of severe liver disease. In practice, screening all new patients with EPP for absence of the IVS3-48C allele to select those with the T/T genotype for mutational analysis of the FECH gene should identify most patients with autosomal recessive disease. Such patients can then be managed clinically with particular attention to their high risk of liver disease.

\section{ACKNOWLEDGEMENTS}

We thank Professor J-C Deybach, INSERM U 409, Hopital Louis Mourier, Colombes, France, for providing information about the FECH IVS3-48C/T SNP in advance of publication. Part of the work was carried out as the project component of the MSc in Clinical Biochemistry and Molecular Biology of the University of Surrey undertaken by MK.

\section{Authors' affiliations}

S D Whatley, N G Mason, M Khan, M N Badminton, G H Elder, Department of Medical Biochemistry and Immunology, University Hospital of Wales and University of Wales College of Medicine, Cardiff, UK

M Zamiri, W S Douglas, N J Wainwright, Department of Dermatology, Monklands Hospital, Airdrie, UK

W N Missaoui, T A Dailey, H A Dailey, Department of Microbiology and Department of Biochemistry and Molecular Biology, University of Georgia, Athens, GA, USA

The work was supported in part by grant DK 32303 from the NIH to HAD.

Conflict of interest: none declared.

Correspondence to: Professor G H Elder, Department of Medical Biochemistry and Immunology, University of Wales College of Medicine, Cardiff CF14 4XN, UK; ghelder@trillium.fsworld.co.uk

Received 5 November 2003

Accepted for publication 1 March 2004

\section{REFERENCES}

1 Anderson KE, Sassa S, Bishop DF, Desnick RJ. Disorders of heme biosynthesis: $X$-linked sideroblastic anemia and the porphyrias. In: Scriver CR, Beaudet AL, Sly WS, Valle D, eds. The metabolic and molecular basis of inherited disease 8th ed. New York: McGraw-Hill, 2001:2961-3062.

2 Bloomer JR. The liver in protoporphyria. Hepatology 1988;8:402-7. 
3 Doss MO, Frank M. Hepatobiliary implications and complications in protoporphyria, a 20-year study. Clin Biochem 1989;22:223-30.

4 Todd DJ. Erythropoietic protoporphyria. Br J Dermatol 1994;131:751-66.

5 Meerman L. Erythropoietic protoporphyria. An overview with emphasis on the liver. Scand J Gastroenterol 2000;35(suppl 232):79-85.

6 Rufenacht UB, Gouya L, Schneider-Yin X, Puy H, Schafer BW, Aquaron R, Nordmann Y, Minder EI, Deybach JC. Systematic analysis of molecular defects in the ferrochelatase gene from patients with erythropoietic protoporphyria. Am J Hum Genet 1998;62:1341-52.

7 Yotsumoto S, Shimada S, Terasaki K, Taketani S, Kobayashi K, Saheki T, Kanzaki T. A novel A(-4)-to-G acceptor splice site mutation leads to three bases insertion in ferrochelatase mRNA in a patient with erythropoietic protoporphyria. J Invest Dermatol 2001;117:159-61.

8 Yasui Y, Muranaka S, Tahara T, Shimizu R, Watanabe S, Horie Y, Nanba E, Uezato $\mathrm{H}$, Takamiyagi A, Taketani S, Akagi R. A new ferrochelatase mutation combined with low expression alleles in a Japanese patient with erythropoietic protoporphyria. Clin Sci 2002;102:501-6.

9 Chen F-P, Risheg H, Liu Y, Bloomer J. Ferrochelatase gene mutations in erythropoietic protoporphyria: focus on liver disease. Cell Mol Biol 2002;48:83-9.

10 Wiman A, Floderus Y, Harper P. Novel mutations and phenotypic effect of the splice site modulator IVS3-48C in nine Swedish families with erythropoietic protoporphyria. J Hum Genet 2003;48:70-6.

11 Nordmann Y, Deybach J-C. Human hereditary porphyrias. In: Dailey HA, eds. Biosynthesis of heme and chlorophylls. New York: McGraw-Hill, 1990:491-542

12 Bonkovsky HL, Bloomer JR, Ebert PS, Mahoney MJ. Heme synthetase deficiency in human protoporphyria: demonstration of the defect in liver and cultured fibroblasts. J Clin Invest 1975;156:1138-48.

13 Nunn AVW, Norris P, Hawk JLM, Cox TM. Zinc chelatase in human lymphocytes: detection of the enzymatic defect in erythropoietic protoporphyria. Anal Biochem 1988;174:146-50.

14 Rossi E, Costin KA, Garcia-Webb P. Ferrochelatase activity in human lymphocytes, as quantified by a new high-performance liquidchromatographic method. Clin Chem 1988;34:2481-5.

15 Went LN, Klasen EC. Genetic aspects of erythropoietic protoporphyria. Ann Hum Genet 1984;48:105-17.

16 Gouya L, Puy H, Lamoril J, Da Silva V, Grandchamp B, Nordmann Y, Deybach J-C. Inheritance in erythropoietic protoporphyria: a common wildtype ferrochelatase allelic variant with low expression accounts for clinical manifestations. Blood 1999;93:2105-10.

17 Schneider-Yin X, Rufenacht UB, Hergersberg M, Schnyder C, Deybach JC, Minder El. Haplotype analysis in determination of the heredity of erythropoietic protoporphyria among Swiss families. J Invest Dermatol 2001;117:1521-5.

18 Gouya L, Puy H, Robreau AM, Bourgeois M, Lamoril J, Da Silva V, Grandchamp B, Deybach J-C. The penetrance of autosomal dominant erythropoietic protoporphyria is modulated by expression of wildtype $\mathrm{FECH}$. Nat Genet 2002;30:27-3

19 Norris PG, Nunn AV, Hawk JLM, Cox TM. Genetic heterogeneity in erythropoietic protoporphyria: a study of the enzymatic defect in nine affected families. J Invest Dermatol 1990;95:260-3.

20 Lamoril J, Boulechfar S, de Verneuil H, Grandchamp B, Nordmann Y, Deybach J-C. Human erythropoietic protoporphyria: two point mutations in the ferrochelatase gene. Biochem Biophys Res Commun 1991;181:594-99.
21 Sarkany RPE, Alexander GJMA, Cox TM. Recessive inheritance of erythropoietic protoporphyria with liver failure. Lancet 1994;343:1394-6

22 Goerz G, Bunselmeyer S, Bolsen K, Schurer NY. Ferrochelatase activities in patients with erythropoietic protoporphyria and their families. Br J Dermatol 1996; 134:880-5.

23 Poh-Fitzpatrick MB, Wang X, Anderson KE, Bloomer JR, Bolwell B, Lichtin AE. Erythropoietic protoporphyria: altered phenotype after bone marrow transplantation for myelogenous leukemia in a patient heteroallelic for ferrochelatase gene mutations. J Am Acad Dermatol 2002;46:861-6.

24 Aplin C, Whatley SD, Thompson P, Hoy T, Fisher P, Singer C, Lovell CR, Elder GH. Late-onset erythropoietic porphyria caused by a chromosome $18 \mathrm{q}$ deletion in erythroid cells. J Invest Dermatol 2001;117:1647-9.

25 Magness ST, Maeda N, Brenner DA. An exon 10 deletion in the mouse ferrochelatase gene has a dominant-negative effect and causes mild protoporphyria. Blood 2002;100:1470-7.

26 Frank J, Nelson J, Wang X, Yang L, Ahmad W, Lam H, Jugert FK, et al. Erythropoietic protoporphyria: identification of novel mutations in the ferrochelatase gene and comparison of biochemical markers versus molecular analysis as diagnostic strategies. J Invest Med 1999;47:278-84.

27 Goerz G, Bolsen K, Bunselmeyer S, Schurer NY. Recessive inheritance of erythropoietic protoporphyria with liver failure. Lancet 1994;554:337.

28 Cox TM. Protoporphyria. In: Kadish KM, Smith KM, Guilard R, eds. The porphyrin handbook, Medical aspects of porphyrias, Vol. 14. Amsterdam: Academic Press, 2003:121-50.

29 Minder El, Gouya L, Schneider-Yin X, Deybach J-C. A genotype-phenotype correlation between null allele mutations in the ferrochelatase gene and liver complication in patients with erythropoietic protoporphyria. Cell Mol Biol 2002;48:91-6.

30 Burden AE, Wu C-K, Dailey TA, Busch JLH, Dhawan IK, Rose JP, Wang B-C, Dailey HA. Human ferrochelatase: crystallization, characterization of the [2Fe-2S] cluster and determination that the enzyme is a homodimer. Biochim Biophys Acta 1999;1435:191-7.

31 Sellers VM, Wu C-K, Dailey TA, Dailey HA. Human ferrochelatase: characterization of substrate-iron binding and proton-abstracting residues. Biochemistry 2001;40:9821-7.

32 Deacon AC, Elder GH. Front line tests for the investigation of suspected porphyria. J Clin Pathol 2001;54:500-7.

33 Schoenfeld N, Mamet R, Minder El, Schneider-Yin X. A 'null allele' mutation is responsible for erythropoietic protoporphyria in an Israeli patient who underwent liver transplantation: relationships among biochemical, genetic and clinical parameters. Blood Cells Mol Dis 2003;30:298-301.

34 Sellers VM, Dailey TA, Dailey HA. Examination of ferrochelatase mutations that cause erythropoietic protoporphyria. Blood 1998;91:3980-5.

35 Schneider-Yin X, Gouya L, Dorsey M, Rufenacht U, Deybach J-C, Ferreira GC. Mutations in the iron-sulfur cluster ligands of the human ferrochelatase gene lead to erythropoietic protoporphyria. Blood 2000;96:1545-9.

36 Rufenacht UB, Gregor A, Gouya L, Tarczynska-Nosal S, Schneider-Yin X, Deybach J-C. New missense mutation in the human ferrochelatase gene in a family with erythropoietic protoporphyria: functional studies and correlation of genotype and phenotype. Clin Chem 2001;47:1112-3.

37 Todd DJ, Hughes AE, Ennis KT, Ward AJ, Barrows D, Nevin NC. Identification of a single base pair deletion ( $40 \mathrm{del} G$ ) in exon 1 of the ferrochelatase gene in patients with erythropoietic protoporphyria. Hum Mol Genet 1993;2:1495-6. 